\title{
The Norwegian PMS2 founder mutation c.989-1G > T shows high penetrance of microsatellite instable cancers with normal immunohistochemistry
}

\author{
Eli Marie Grindedal ${ }^{1,2^{*}}$, Harald Aarset ${ }^{3}$, Inga Bjørnevoll ${ }^{3}$, Elin Røyset ${ }^{3}$, Lovise Mæhle ${ }^{1,2}$, Astrid Stormorken $^{1,2}$,
} Cecilie Heramb ${ }^{1,2}$, Heidi Medvik ${ }^{1,2}$, Pål Møller $^{1}$ and Wenche Sjursen ${ }^{3,4}$

\begin{abstract}
Background: Using immunohistochemistry (IHC) to select cases for mismatch repair (MMR) genetic testing, we failed to identify a large kindred with the deleterious PMS2 mutation c.989-1G > T. The purpose of the study was to examine the sensitivity of $\mathrm{IHC}$ and microsatellite instability-analysis (MSI) to identify carriers of the mutation, and to estimate its penetrance and expressions.

Methods: All carriers and obligate carriers of the mutation were identified. All cancer diagnoses were confirmed. $\mathrm{IHC}$ and MSI-analysis were performed on available tumours. Penetrances of cancers included in the Amsterdam and the Bethesda Criteria, for MSI-high tumours and MSI-high and low tumours were calculated by the Kaplan-Meier algorithm.

Results: Probability for co-segregation of the mutation and cancers by chance was 0.000004 . Fifty-six carriers or obligate carriers were identified. There was normal staining for PMS2 in 15/18 (83.3\%) of tumours included in the AMS1/AMS2/Bethesda criteria. MSI-analysis showed that 15/21 (71.4\%) of tumours were MSI-high and 4/21 (19.0\%) were MSI-low. Penetrance at 70 years was 30.6\% for AMS1 cancers (colorectal cancers), 42.8\% for AMS2 cancers, 47.2\% for Bethesda cancers, 55.6\% for MSI-high and MSI-low cancers and 52.2\% for MSI-high cancers.
\end{abstract}

Conclusions: The mutation met class 5 criteria for pathogenicity. IHC was insensitive in detecting tumours caused by the mutation. Penetrance of cancers that displayed MSI was 56\% at 70 years. Besides colorectal cancers, the most frequent expressions were carcinoma of the endometrium and breast in females and stomach and prostate in males.

Keywords: Lynch syndrome, PMS2, Immunohistochemistry, Microsatellite instability, Penetrance, Expression

\section{Background}

Lynch Syndrome (LS) is a multi organ cancer syndrome caused by germline mutations in the four MMR genes MLH1, MSH2, MSH6 and PMS2. The tumour spectrum includes colorectal- and endometrial cancer as the predominant cancers, and carcinoma of the upper uroepithelial tract, ovary, hepatobiliary tract, brain, stomach and prostate with lower frequency.

\footnotetext{
* Correspondence: eli.marie.grindedal@ous-hf.no

${ }^{1}$ Research Group on Inherited Cancer, Department of Medical Genetics, Oslo University Hospital, Oslo, Norway

${ }^{2}$ Section of Inherited Cancer, Department of Medical Genetics, Oslo

University Hospital, Oslo, Norway

Full list of author information is available at the end of the article
}

The PMS2 gene was the last of the four MMR genes to be identified as a cause of LS [1]. It has been suggested that PMS2 mutations may be associated with a later age of onset of cancer than $M L H 1$ and $M S H 2$ mutations [1]. However, reports are few and the exact penetrance and expression of mutations in PMS2 is considered unknown [2].

Tumours caused by a pathogenic germline mutation in one of the MMR genes have specific characteristics. Firstly, they display microsatellite instability (MSI). Microsatellites are DNA-sequences found throughout the genome where one or units of two or more nucleotides are repeated a certain number of times. A change 
in the length of these units because of insertion or deletion of repeating units during DNA replication and a failure of the MMR complex to correct these errors is called MSI. Usually, a panel of six markers is used to investigate whether a tumour displays MSI or not. If there is instability in two or more markers the tumour is considered MSI-high. If only one marker shows instability, the tumour is considered MSI-low. Secondly, tumours caused by pathogenic mutations in one of the MMR genes lack expression of the gene product from the mutated gene $[3,4]$. The presence or absence of gene products from the MMR genes is investigated by immunohistochemistry (IHC) on formaline-fixated tumour specimens. Genetic testing of tumour tissue has several advantages. It is a cheap method that can be used to select patients for more extensive testing of blood by Sanger sequencing and MLPA and one may test deceased relatives.

In general, the sensitivity of MSI and IHC to detect carriers of MMR-mutations is considered to be high $[5,6]$. However, differences between the genes have been described. It has recently been reported that $95 \%$ of cancers occurring in carriers of mutations in $\mathrm{MLH} 1$ or $\mathrm{MSH} 2$ lack staining of gene product from the mutated gene, compared to $71 \%$ of cancers in MSH6 mutation carriers [7]. In addition, whereas $90 \%$ of tumours caused by $M L H 1$ and MSH2 mutations display MSI [8], tumours caused by MSH6 mutations show lower levels of MSI and may be classified as MSS or MSI-low [6]. The clinical sensitivity of IHC and MSI to detect carriers of PMS2-mutations is not known [9].

It has been demonstrated that PMS2-mutation carriers develop cancers that show selective loss of PMS 2 by IHC $[1,10,11]$ and that this is advocated to be followed by PMS2 mutation testing in blood [1].

In 1999 a large family fulfilling the revised Amsterdam Criteria was referred to the Section for Inherited Cancer at the Oslo University Hospital. IHC was performed on tumours from several of the affected relatives during the following years, showing normal staining of all MMRgenes. Despite the normal staining in tumour tissue, a blood sample from a woman with a prospectively detected endometrial cancer was tested for mutations in all the MMR genes when such testing became available. A pathogenic splice variant PMS2 c.989-1G > T was detected. The variant had previously been reported [12]. It is now found to be a local frequent mutation in MidNorway (unpublished result), and it has also been detected in families living in the south of Norway.

The identification of the mutation in the large family had been delayed several years due to the normal IHCresults in mutation carriers. The aim of the study was to examine the sensitivity of IHC and MSI to identify carriers in cancer cases, and the penetrance and expressions of the mutation.

\section{Methods}

All carriers and obligate carriers of the mutation were identified in the databases at the Section for Inherited Cancer at Oslo University Hospital and at the Department of Medical Genetics at St. Olav's Hospital in Trondheim. All cancer diagnoses were confirmed from medical files or from The Cancer Registry of Norway.

IHC and MSI-analysis were performed on paraffin blocks from all available tumours. The analyses were performed as described in Sjursen et al. [12]. The PMS2 antibody was monoclonal, clone A16-4, from BD Pharmingen ( $\mathrm{CA}$, USA). BD Pharmingen reported to have used recombinant human PMS2 C-terminal half (codon 431-862) as immunogen in antibody development. DNA mutation analyses for the PMS2 variant c.989-1G > T were performed by Sanger sequencing and the PCR primers and conditions are also described in Sjursen et al. 2009 [12].

As previously described, demonstrated and obligate mutation carriers were included in segregation analysis to determine probability for co-segregation of the mutation and disease by chance [13].

The Kaplan-Meier Algorithm was used to calculate time from birth to any cancer in demonstrated or obligate carriers. Also, penetrances were calculated separately for MSI-high tumours and for tumours that were MSI-high or MSI-low. In the latter analyses cancers with inconclusive results of MSI or no MSI performed were excluded.

No named data was exported from the medical files. All patients alive had at least one genetic counseling session, and all genetic testing included written informed consent and were conducted according to national legislation. The study was approved by the Ethical review board (ref S02030) and the Norwegian Data Inspectorate (ref 2001/2988-2). The present report is one in a series to meet the request from The Norwegian Parliament to report the results of our activities.

\section{Results}

Forty-eight carriers and 8 obligate carriers were identified, giving a total of 56 individuals that were included in the study, 33 women and 23 men. 19/56 (33.9\%) were affected with at least one cancer included in the AMS1/ AMS2/Bethesda criteria, and 22/56 (39.3\%) were affected with any cancer, 13 women and 9 men. Segregation analysis showed 19 informative meioses, giving a probability of co-segregation by chance of $(1 / 2)^{18}$ corresponding with a probability of pathogenicity of 0.999996 .

The most frequently observed cancer both in men and women was colorectal cancer, occurring in 12/22 (54.5\%) of the affected with a mean age of 46.9 years (range 26-75). In women colorectal-, endometrial- and breast cancer occurred in $6 / 13$ (46.2\%), 5/13 (38.5\%) and 3/13 
Table 1 Expression of cancers in carriers of PMS2 c.989-1G > T

\begin{tabular}{llll}
\hline Cancer & All $(\boldsymbol{n}=\mathbf{2 2})$ & Women $(\boldsymbol{n}=\mathbf{1 3})$ & Men $(\boldsymbol{n}=\mathbf{9})$ \\
\hline Colorectum & $12(54.5 \%)$ & $6(46.2 \%)$ & $6(66.7 \%)$ \\
Stomach & $3(13.6 \%)$ & - & $3(33.3 \%)$ \\
Kidney & $1(4.5 \%)$ & $1(7.7 \%)$ & - \\
Malignant melanoma & $1(4.5 \%)$ & $1(7.7 \%)$ & - \\
Sarcoma & $1(4.5 \%)$ & $1(7.7 \%)$ & - \\
Endometrium & - & $5(38.5 \%)$ & - \\
Ovary & - & $1(7.7 \%)$ & - \\
Breast & - & $3(23.1 \%)$ & - \\
Prostate & - & - & $2(22.2 \%)$ \\
\hline
\end{tabular}

(23.1\%) respectively. In men, colorectal-,gastric- and prostate cancer, occurred in 6/9 (66.7\%), 3/9 (33.3\%) and 2/9 (22.2\%) respectively (Table 1 ).

In sum, IHC was performed on 24 tumours, and $21 / 24$ (87.5\%) showed expression of PMS2. Of tumours included in AMS1/AMS2/Bethesda criteria 15/18 (83.3\%) showed normal staining for PMS2 with IHC. Three breast cancers, one sarcoma, one prostate cancer and one renal cancer, all showed normal IHC for PMS2 (Figure 1).

MSI analysis was performed on altogether 23 tumours in mutation carriers, and 21 gave conclusive results. Nineteen out of twenty-one (90.5\%) of the tumours were MSI. Fifteen out of twenty-one (71.4\%) were MSI-high and 4/21 (19.0\%) of the tumours were MSI-low. The tumours that were MSI-low were one endometrial cancer, one breast cancer, one prostate cancer and one gastric cancer. Six of the tumours available for MSI-analyses were not included in the AMSI/AMSII/Bethesda criteria; three breast cancers, one renal cancer, one prostate cancer and one sarcoma. All but one of the breast cancers and the renal cancer were MSI. The sarcoma and one breast cancer were MSI-high. The prostate cancer and the other breast cancer were MSI-low (Table 2).
The three tumours that showed no staining of PMS2 by IHC were two colorectal cancers and one endometrial cancer. MSI-analysis was performed on one of the colorectal cancers and on the endometrial cancer, and both tumours were MSI-high.

Penetrance at 30, 50 and 70 years was 1.8\%, 15.7\% and $30.6 \%$ for AMS1 cancers (colorectal cancers), 1.8\%, 18\% and $42.8 \%$ for AMS2 cancers, 3.6\%, 20.9\% and $47.2 \%$ for Bethesda cancers and 3.6\%, 22.8\%, and $60.5 \%$ for any cancer. Penetrance of cancers that were either MSI-high or MSI-low at 30, 50 and 70 years was $3.9 \%, 17.2 \%$ and $55.6 \%$. Penetrance of cancers that were MSI-high at 30, 50 and 70 years was $3.9 \%, 17.2 \%$ and $52.2 \%$ (Figures 2, 3, 4, 5, 6 and 7).

\section{Discussion}

The splice mutation PMS2 c.989-1G > T met the InSiGHT criteria class 5 for pathogenicity [14]: mRNA analysis showed that it caused two abnormal transcripts, it cosegregates with disease, more than 2 tumours were MSI-high and has a population frequency $<1 \%$. However, whereas $90 \%$ of tumours in mutation carriers were MSIhigh or MSI-low, only $12.5 \%$ of tumours showed abnormal staining of PMS2 by IHC. Penetrance of MSI cancers at age 70 was $56 \%$.

Several studies have demonstrated that PMS2 mutation carriers can be identified among patients with MSI-high tumours and/or loss of PMS2 in tumour tissue. Gill and colleagues found that $72 \%$ of MSI-high tumours, showing normal staining for MLH1, MSH2 and MSH6 showed selective loss of PMS2 [11]. In a series of 1048 unselected consecutive cases of CRC selective loss of PMS2 was observed in $1.5 \%$ of tumours, which was similar to the frequency of loss of MSH2. Several mutations in the PMS2 gene were identified among the patients with PMS2deficient tumours [10]. Accordingly, tumour testing by IHC and MSI is used as a screening tool to select patients for genetic testing for mutations in PMS2. However, the clinical sensitivity of IHC and MSI to detect PMS2 mutation carriers is not known. In our series, IHC alone would
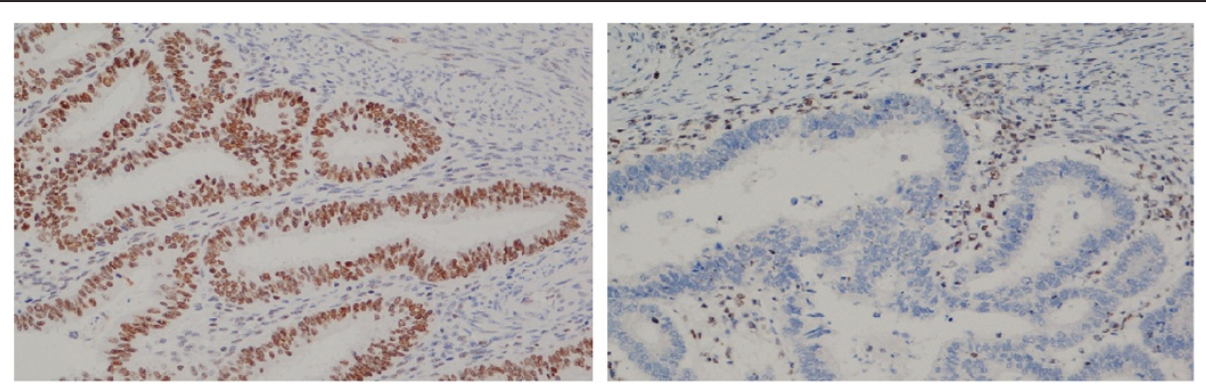

Figure 1 Endometrial cancers in carriers of PMS2 c.989-1G > T with and without expression of PMS2. IHC analysis of two adenocarcinomas of the endometrium. Immunhistochemical reaction shows expression (left) or no expression (right) of PMS2. Magnification $\times 20$. Lymphocytes in the tumour sample provide positive control. Both tumours displayed MSI. 
Table 2 IHC/MSI profile according to type of cancer

\begin{tabular}{|c|c|c|c|c|c|c|c|}
\hline Tumour type & IHC performed & PMS2 expressed & Loss of PMS2 expression & MSI performed & MSS & MSI high & MSI low \\
\hline Colorectal & 11 & 9 & 2 & 9 & & 9 & \\
\hline Gastric & 2 & 2 & 0 & 2 & & 1 & 1 \\
\hline Endometrial & 4 & 3 & 1 & 3 & & 2 & 1 \\
\hline Prostate & 1 & 1 & 0 & 1 & & & 1 \\
\hline Ovarian & 1 & 1 & 0 & 1 & & 1 & \\
\hline Breast & 3 & 3 & 0 & 3 & 1 & 1 & 1 \\
\hline Sarcoma & 1 & 1 & 0 & 1 & & 1 & \\
\hline Renal & 1 & 1 & 0 & 1 & 1 & & \\
\hline Sum & 24 & 21 (87.5\%) & 3 & 21 & 2 & $15(71.4 \%)$ & $4(19.0 \%)$ \\
\hline
\end{tabular}

have failed to detect about $85 \%$ of the PMS2-mutation carriers. We have previously reported a homozygous carrier of PMS2 c.989-1G > T with Turcot syndrome [12]. cDNAanalysis demonstrated that the splice site mutation leads to two abnormal transcripts, one missing exon 10 and the other missing the first 27 nucleotides of exon 10. The latter may be caused by splicing with a cryptic acceptor site. The first part of exon 10 is highly conserved and it contains the catalytically important 340Lys residue for ATP hydrolysis [15]. It also contains the end of the functional domains DNA mismatch repair protein N-terminal and C-terminal (IPR014763 and IPR013507 respectively). None of the transcripts led to frame shift, and this may prevent them from being degraded by nonsense mediated mRNA decay $[16,17]$. The normal IHC may therefore reflect that the transcripts are translated into non-functional proteins being transferred to the nucleus where they bind

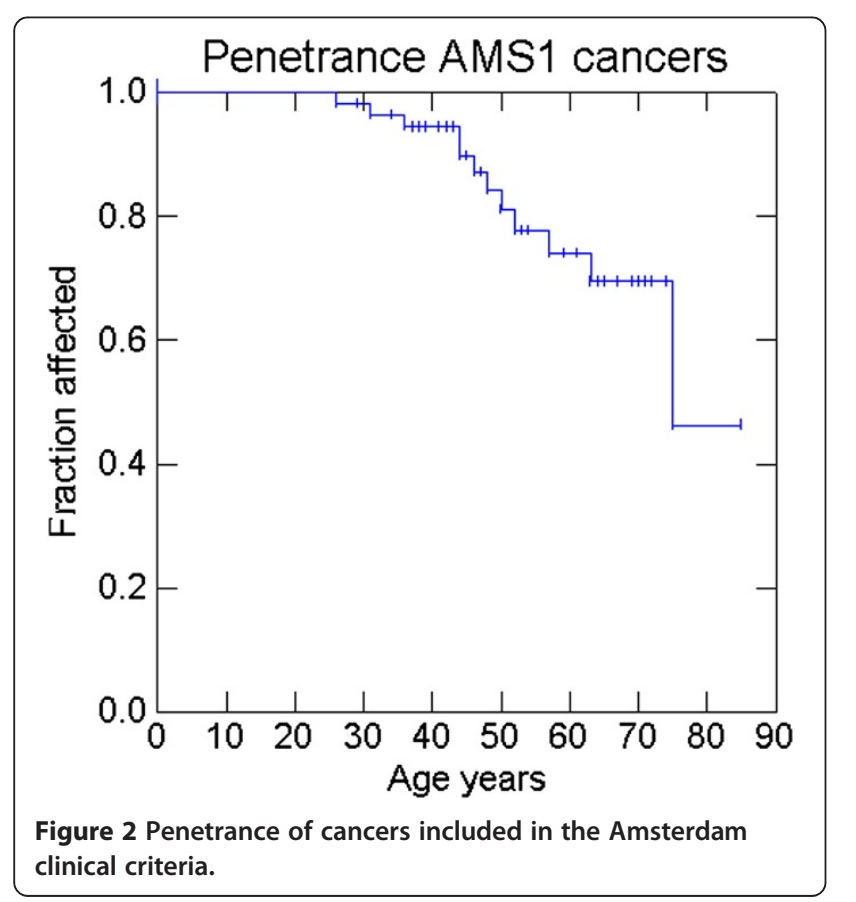

to the epitope of the PMS2 antibody. This hypothesis is supported by the fact that the antibody binds to somewhere between codon 431-862 which is downstream to the deletions in the two gene products of the mutation. Further the PMS2 exon 10 deletions in the transcripts do neither affect the MLH1 binding domain (codon 675-850 [18]) nor the nuclear localisation signal (codon 625-632 [19]). Thus, the low sensitivity of IHC to detect tumours caused by the PMS2 splice mutation is in keeping with a non-functional protein located at the right place in the cell detectable by IHC. Interestingly, a recent study on discrepancies between IHC and MSI results reported that of 646 consecutive tumours investigated, as many as $11.8 \%$ of the tumours that were MSI high showed normal expression of all MMR genes. Eight of these 12 tumours were from patients that had a first degree relative with a LS associated cancer. It is not known how many of the

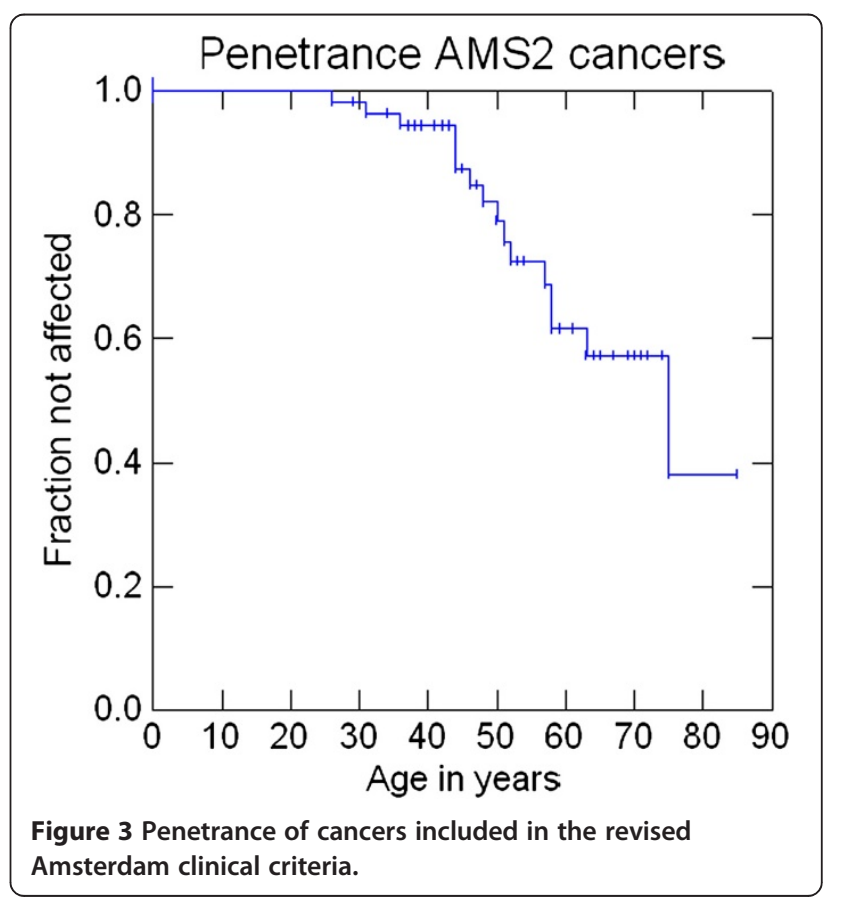




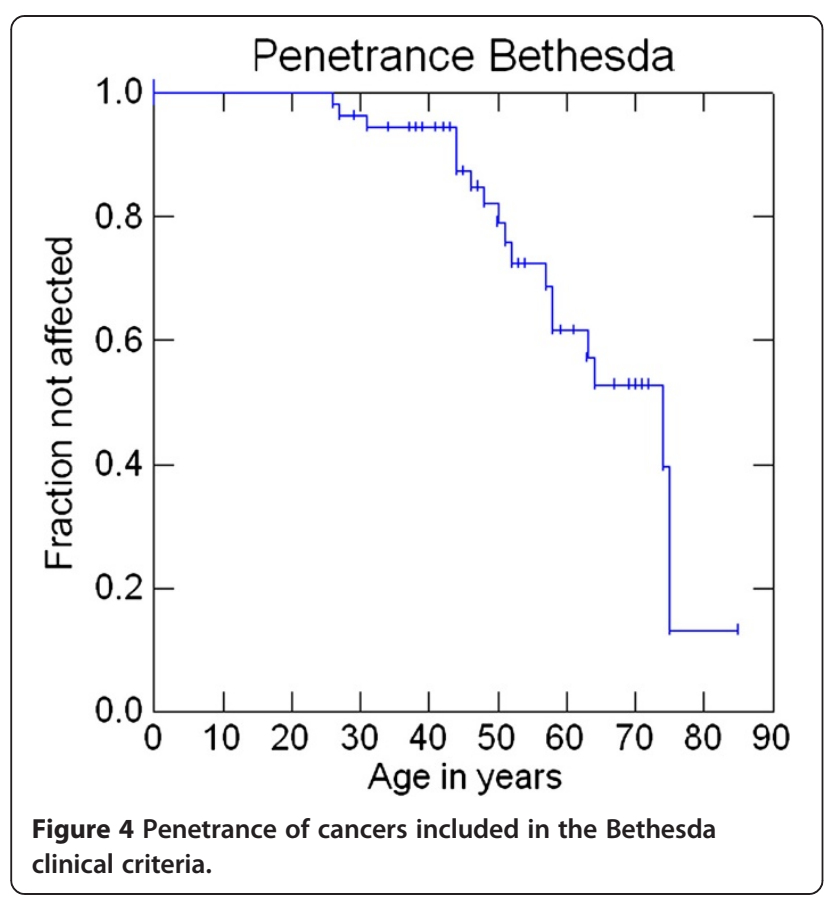

patients with MSI-high tumours that carried a MMR mutation [20].

We observed that all colorectal-, gastric, endometrial-, prostate- and ovarian cancers and $2 / 3$ of breast cancers occurring in carriers of the PMS2 mutation displayed MSI. In addition, the sarcoma was also MSI high. Of the tumours investigated, only the renal cancer and one breast cancer were MSS. MSI analysis is considered a sensitive method to identify MMR mutation carriers,

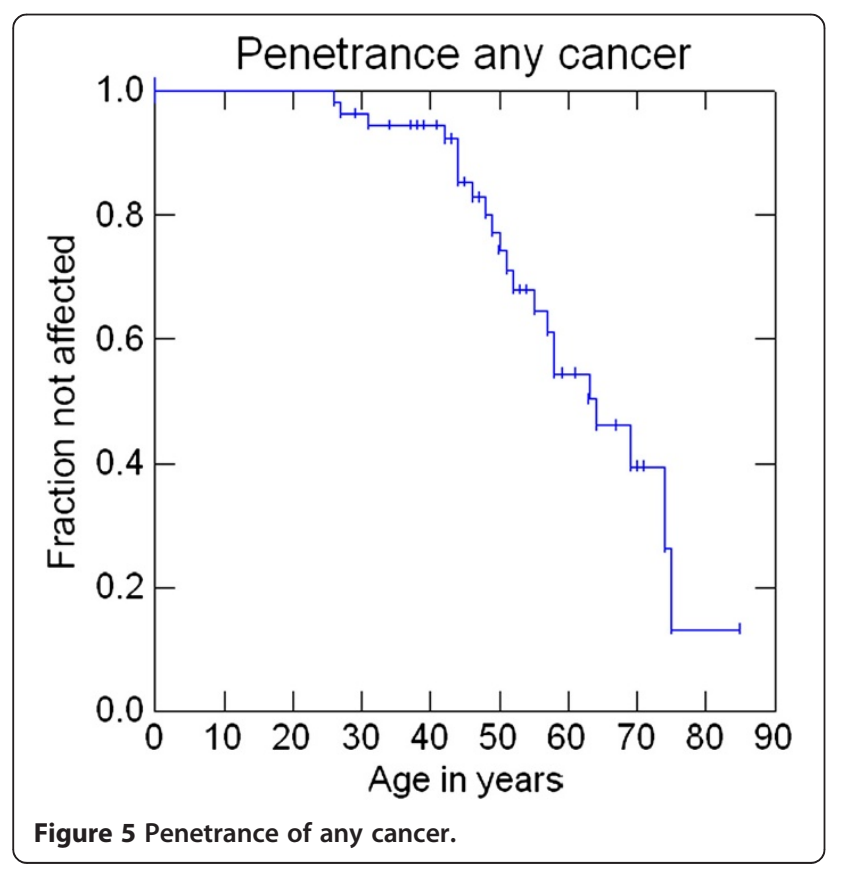

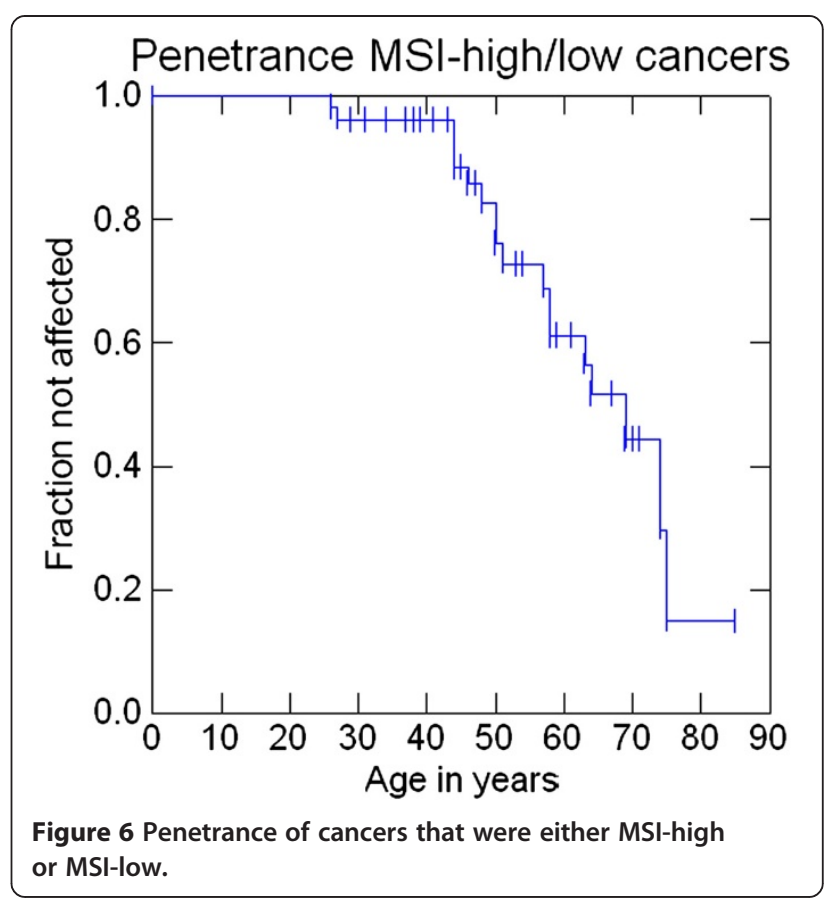

and one could hypothesize that all cancers caused by a pathogenic germline MMR mutation would display MSI. However, it is well known that tumours caused by MSH6 mutations may show lower levels of MSI and may be classified as MSS or MSI-low [6]. The fraction of tumours that display MSI may also be different for different cancer types. Gylling and colleagues reported that $100 \%$ of gastric cancers and more than $90 \%$ of colorectal cancers in MMR mutation carriers $(>90 \%$ were

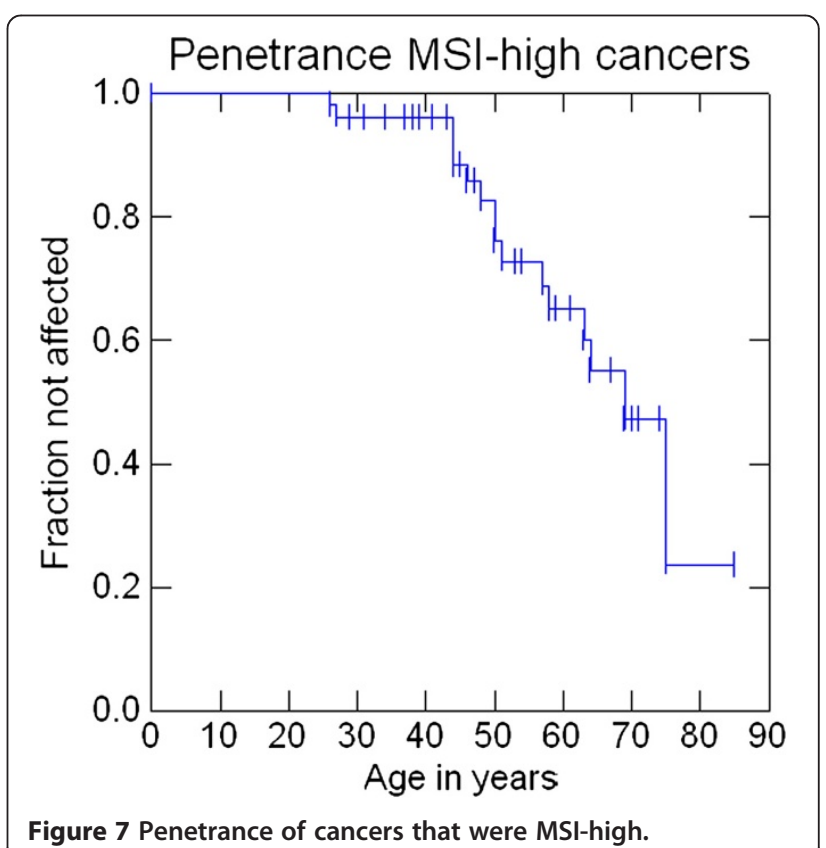


carriers of MLH1 mutations) were MSI high compared to $63 \%$ of endometrial cancers and $25 \%$ of renal cancers [21]. Similarly, it has been reported that $60 \%$ and $45 \%$ of breast cancers occurring in $M S H 2$ and $M L H 1$ mutation carriers respectively were MSI high, whereas all breast cancers in MSH6 mutation carriers were MSS [22]. Our observations indicate that MSI analysis may be used to identify PMS2 mutation carriers among patients with extra-colonic as well as colonic cancers. However, larger numbers are required to assess whether the fraction of colonic and extra-colonic tumours that display MSI are different from the other MMR genes.

A recent study has demonstrated that IHC has a low sensitivity in identifying pathogenic MSH6-mutations, as almost $24 \%$ of adenocarcinomas in carriers of pathogenic MSH6 mutations showed normal staining of this gene [23]. The explanation for this finding remains unknown. We observed that in carriers of PMS2 c.989-1G > T 83\% of cancers included in the AMS1/AMS2/Bethesda clinical criteria had normal expression of PMS2. Whether the sensitivity of IHC to identify carriers of PMS2-mutations is similar to MSH6 or to the high sensitivity reported for tumours caused by MLH1- or MSH2-mutations cannot be addressed in the present study where carriers of only one mutation were included, but needs further clarification.

The exact penetrance and expression associated with mutations in PMS2 is not known [2]. Previous reports have referred to the gene as giving an attenuated form of Lynch Syndrome, a lower risk of CRC and a later age of onset than what has been described for MLH1 and MSH2 [1]. Several studies have also demonstrated that the majority of families do not fulfill the clinical criteria for LS $[1,10,11,24,25]$. We observed that penetrance at 70 years for CRC was $30 \%$ and $56 \%$ for MSI cancers. This may be in keeping with previous studies, and may indicate that risk of CRC is lower than what has been reported for carriers of mutations in MLH1 and MSH2 [26]. We also observed that after colorectal cancer, endometrial- and breast cancer were the most commonly observed cancers in women, and gastric- and prostate cancers in men.

\section{Conclusions}

The class 5 pathogenic splice mutation PMS2 c.989-1G > T had a penetrance for MSI cancers of $56 \%$ at 70 years of age. Colorectal cancer was most frequently seen, while expressions included breast-, gastric- and prostate cancers as well. IHC detected only $12.5 \%$ of the tumours caused by the mutation. Our observations illustrate the importance of performing both IHC and MSI analysis when selecting patients for MMR genetic testing.

\section{Abbreviations}

AMS1: The original Amsterdam clinical criteria; AMS2: The revised Amsterdam clinical criteria; Bethesda: The Bethesda clinical criteria; IHC: Immunohistochemistry; LS: Lynch Syndrome; MMR: Mismatch repair; MSI: Microsatellite instability.

\section{Competing interests}

The authors declare that they have no competing interests.

\section{Authors' contributions}

EMG took part in the genetic work up of the families including genetic counseling, contributed to the design of the study, carried out the compilation of the data, the statistical analysis, and coordinated formatting and writing of the manuscript. HA performed the IHC tumour testing. IB took part in the genetic work up of the families including genetic counseling and compiled the data from St. Olavs Hospital. ER performed the IHC tumour testing. LM was involved in the genetic work up of the families including genetic counseling, conceived the study and was involved in its design and formatting of the manuscript. AS was involved in the genetic work up of the families including genetic counseling, was involved in the study design, and formatting of the manuscript. $\mathrm{CH}$ was involved in the genetic work up of the families and contributed to the formatting of the manuscript. HM was involved in the genetic work up of the families including genetic counseling, and contributed to the formatting of the manuscript. PM was involved in the genetic work up of the families, including the genetic counseling, conceived the study, contributed to the design of the study, the statistical analysis and the formatting and writing of the manuscript. WS performed the molecular genetic testing, conceived the study and was involved in its design and formatting of the manuscript. All authors read and approved the final manuscript.

\section{Acknowledgements}

We would like to thank all genetic counselors and Medical Doctors at St. Olav University Hospital and Oslo University Hospital who have counseled the family members. We would also like to thank the staff at the Department of Pathology and Medical Genetics at St. Olavs University Hospital who have performed the molecular genetic testing.

\section{Author details}

${ }^{1}$ Research Group on Inherited Cancer, Department of Medical Genetics, Oslo University Hospital, Oslo, Norway. ${ }^{2}$ Section of Inherited Cancer, Department of Medical Genetics, Oslo University Hospital, Oslo, Norway. ${ }^{3}$ Department of Pathology and Medical Genetics, St. Olavs University Hospital, Trondheim, Norway. ${ }^{4}$ Department of Laboratory Medicine Children's and Women's Health, Norwegian University of Science and Technology, Trondheim, Norway.

Received: 30 January 2014 Accepted: 9 April 2014 Published: 21 April 2014

\section{References}

1. Hendriks YM, Jagmohan-Changur S, van der Klift HM, Morreau $H$, van Puijenbroek M, Tops C, van Os T, Wagner A, Ausems MG, Gomez E, Breuning MH, Bröcker-Vriends AH, Vasen HF, Wijnen JT: Heterozygous mutations in PMS2 cause hereditary nonpolyposis colorectal carcinoma (Lynch syndrome). Gastroenterology 2006, 130(2):312-322.

2. Vasen HF, Blanco I, Aktan-Collan K, Gopie JP, Alonso A, Aretz S, Bernstein I, Bertario L, Burn J, Capella G, Colas C, Engel C, Frayling IM, Genuardi M, Heinimann K, Hes FJ, Hodgson SV, Karagiannis JA, Lalloo F, Lindblom A, Mecklin JP, Møller P, Myrhoj T, Nagengast FM, Parc Y, Ponz De Leon M, Renkonen-Sinisalo L, Sampson JR, Stormorken A, Sijmons RH, et al: Revised guidelines for the clinical management of Lynch syndrome (HNPCC): recommendations by a group of European experts. Gut 2013, 62(6):812-823.

3. Leach FS, Polyak K, Burrell M, Johnson KA, Hill D, Dunlop MG, Wyllie AH, Peltomaki P, De la Chapelle A, Hamilton SR, Kinzler KW, Vogelstein B: Expression of the human mismatch repair gene hMSH2 in normal and neoplastic tissues. Cancer Res 1996, 56(2):235-240.

4. Thibodeau SN, French AJ, Roche PC, Cunningham JM, Tester DJ, Lindor NM, Moslein G, Baker SM, Liskay RM, Burgart LJ, Honchel R, Halling KC: Altered expression of $\mathrm{hMSH} 2$ and $\mathrm{hMLH} 1$ in tumors with microsatellite instability and genetic alterations in mismatch repair genes. Cancer Res 1996, 56(21):4836-4840.

5. Shia J: Immunohistochemistry versus microsatellite instability testing for screening colorectal cancer patients at risk for hereditary nonpolyposis colorectal cancer syndrome. Part I. The utility of immunohistochemistry. J Mol Diagn 2008, 10(4):293-300. 
6. Zhang L: Immunohistochemistry versus microsatellite instability testing for screening colorectal cancer patients at risk for hereditary nonpolyposis colorectal cancer syndrome. Part II. The utility of microsatellite instability testing. J Mol Diagn 2008, 10(4):301-307.

7. Kastrinos F, Steyerberg EW, Balmaña J, Mercado R, Gallinger S, Haile R, Casey G, Hopper JL, LeMarchand L, Lindor NM, Newcomb PA, Thibodeau SN, Syngal S, Colon Cancer Family Registry: Comparison of the clinical prediction model PREMM $(1,2,6)$ and molecular testing for the systematic identification of Lynch syndrome in colorectal cancer. Gut 2013, 62(2):272-279.

8. Palomaki GE, McClain MR, Melillo S, Hampel HL, Thibodeau SN: EGAPP supplementary evidence review: DNA testing strategies aimed at reducing morbidity and mortality from Lynch syndrome. Genet Med 2009, 11(1):42-65.

9. Weissman SM, Burt R, Church J, Erdman S, Hampel H, Holter S, Jasperson K, Kalady MF, Haidle JL, Lynch HT, Palaniappan S, Wise PE, Senter L: Identification of individuals at risk for Lynch syndrome using targeted evaluations and genetic testing: National Society of Genetic Counselors and the Collaborative Group of the Americas on Inherited Colorectal Cancer joint practice guideline. J Genet Couns 2012, 21(4):484-493.

10. Truninger K, Menigatti M, Luz J, Russell A, Haider R, Gebbers JO, Bannwart F, Yurtsever H, Neuweiler J, Riehle HM, Cattaruzza MS, Heinimann K, Schär P, Jiricny J, Marra G: Immunohistochemical analysis reveals high frequency of PMS2 defects in colorectal cancer. Gastroenterology 2005, 128(5):1160-1171.

11. Gill S, Lindor NM, Burgart LJ, Smalley R, Leontovich O, French AJ, Goldberg RM, Sargent DJ, Jass JR, Hopper JL, Jenkins MA, Young J, Barker MA, Walsh MD Ruszkiewicz AR, Thibodeau SN: Isolated loss of PMS2 expression in colorectal cancers: frequency, patient age, and familial aggregation. Clin Cancer Res 2005, 11(18):6466-6471.

12. Sjursen W, Bjørnevoll I, Engebretsen LF, Fjelland K, Halvorsen T, Myrvold HE A homozygote splice site PMS2 mutation as cause of Turcot syndrome gives rise to two different abnormal transcripts. Fam Cancer 2009, 8(3):179-186.

13. Møller P, Clark N, Mæhle L: A SImplified method for Segregation Analysis (SISA) to determine penetrance and expression of a genetic variant in a family. Hum Mutat 2011, 32(5):568-571.

14. Thompson BA, Spurdle AB, Plazzer JP, Greenblatt MS, Akagi K, Al-Mulla F, Bapat B, Bernstein I, Capellá G, Den Dunnen JT, Du Sart D, Fabre A, Farrell MP, Farrington SM, Frayling IM, Frebourg T, Goldgar DE, Heinen CD, Holinski-Feder E, Kohonen-Corish M, Robinson KL, Leung SY, Martins A, Moller P, Morak M, Nystrom M, Peltomaki P, Pineda M, Qi M, Ramesar R, et al: Application of a 5-tiered scheme for standardized classification of 2,360 unique mismatch repair gene variants in the InSiGHT locusspecific database. Nat Genet 2013, [Epub ahead of print].

15. Guarné A, Junop MS, Yang W: Structure and function of the N-terminal 40 kDa fragment of human PMS2: a monomeric GHL ATPase. EMBO J 2001, 20(19):5521-5531.

16. Andreutti-Zaugg C, Scott RJ, Iggo R: Inhibition of nonsense-mediated messenger RNA decay in clinical samples facilitates detection of human $\mathrm{MSH} 2$ mutations with an in vivo fusion protein assay and conventional techniques. Cancer Res 1997, 57(15):3288-3293.

17. Behm-Ansmant I, Kashima I, Rehwinkel J, Saulière J, Wittkopp N, Izaurralde E: mRNA quality control: an ancient machinery recognizes and degrades mRNAs with nonsense codons. FEBS Lett 2007, 581(15):2845-2853.

18. Guerrette S, Acharya S, Fishel R: The interaction of the human MutL homologues in hereditary nonpolyposis colon cancer. J Biol Chem 1999, 274(10):6336-6341.

19. Leong V, Lorenowicz J, Kozij N, Guarné A: Nuclear import of human MLH1, PMS2, and MutLalpha: redundancy is the key. Mol Carcinog 2009, 48(8):742-750.

20. Bartley AN, Luthra R, Saraiya DS, Urbauer DL, Broaddus RR: Identification of cancer patients with Lynch syndrome: clinically significant discordances and problems in tissue-based mismatch repair testing. Cancer Prev Res (Phila) 2012, 5(2):320-327.

21. Gylling AH, Nieminen TT, Abdel-Rahman WM, Nuorva K, Juhola M, Joensuu El, Järvinen HJ, Mecklin JP, Aarnio M, Peltomäki PT: Differential cancer predisposition in Lynch syndrome: insights from molecular analysis of brain and urinary tract tumors. Carcinogenesis 2008, 29(7):1351-1359.

22. Lotsari JE, Gylling A, Abdel-Rahman WM, Nieminen T, Aittomäki K, Friman M, Pitkänen R, Aarnio M, Järvinen HJ, Mecklin JP, Kuopio T, Peltomäki P: Breast carcinoma and Lynch syndrome: molecular analysis of tumors arising in mutation carriers, non-carriers, and sporadic cases. Breast Cancer Res 2012, 12(3):R90.

23. Okkels $H$, Lindorff-Larsen $K$, Thorlasius-Ussing O, Vyberg M, Lindebjerg J, Sunde L, Bernstein I, Klarskov L, Holck S, Krarup HB: MSH6 mutations are frequent in hereditary nonpolyposis colorectal cancer families with normal pMSH6 expression as detected by immunohistochemistry. Appl Immunohistochem Mol Morphol 2012, 20(5):470-477.

24. Sjursen W, Haukanes Bl, Grindedal EM, Aarset $\mathrm{H}$, Stormorken A, Engebretsen LF, Jonsrud C, Bjørnevoll I, Andresen PA, Ariansen S, Lavik LA, Gilde B, BowitzLothe IM, Maehle L, Møller P: Current clinical criteria for Lynch syndrome are not sensitive enough to identify MSH6 mutation carriers. J Med Genet 2010, 47(9):579-585.

25. Borràs E, Pineda M, Cadiñanos J, Del Valle J, Brieger A, Hinrichsen I, Cabanillas R, Navarro M, Brunet J, Sanjuan X, Musulen E, van der Klift H, Lázaro C, Plotz G, Blanco I, Capellá G: Refining the role of PMS2 in Lynch syndrome: germline mutational analysis improved by comprehensive assessment of variants. J Med Genet 2013, 50(8):552-563.

26. Senter L, Clendenning M, Sotamaa K, Hampel H, Green J, Potter JD, Lindblom A, Lagerstedt K, Thibodeau SN, Lindor NM, Young J, Winship I, Dowty JG, White DM, Hopper JL, Baglietto L, Jenkins MA, de la Chapelle A: The clinical phenotype of Lynch syndrome due to germ-line PMS2 mutations. Gastroenterology 2008, 135(2):419-428.

\section{doi:10.1186/1897-4287-12-12}

Cite this article as: Grindedal et al.: The Norwegian PMS2 founder mutation c.989-1G > T shows high penetrance of microsatellite instable cancers with normal immunohistochemistry. Hereditary Cancer in Clinical Practice 2014 12:12.

\section{Submit your next manuscript to BioMed Central and take full advantage of:}

- Convenient online submission

- Thorough peer review

- No space constraints or color figure charges

- Immediate publication on acceptance

- Inclusion in PubMed, CAS, Scopus and Google Scholar

- Research which is freely available for redistribution

Submit your manuscript at www.biomedcentral.com/submit
C) Biomed Central 